\title{
Contribuições para a Construção da Historiografia da Psicologia Educacional e Escolar no Brasil
}

Contributions For The Development Of The Historiography Of Educational And School Psychology In Brazil

Contribuciones Para La Construcción De La Historiografía De La Psicología Educacional Y Escolar En El Brasil

Deborah Rosária Barbosa

Universidade de São Paulo

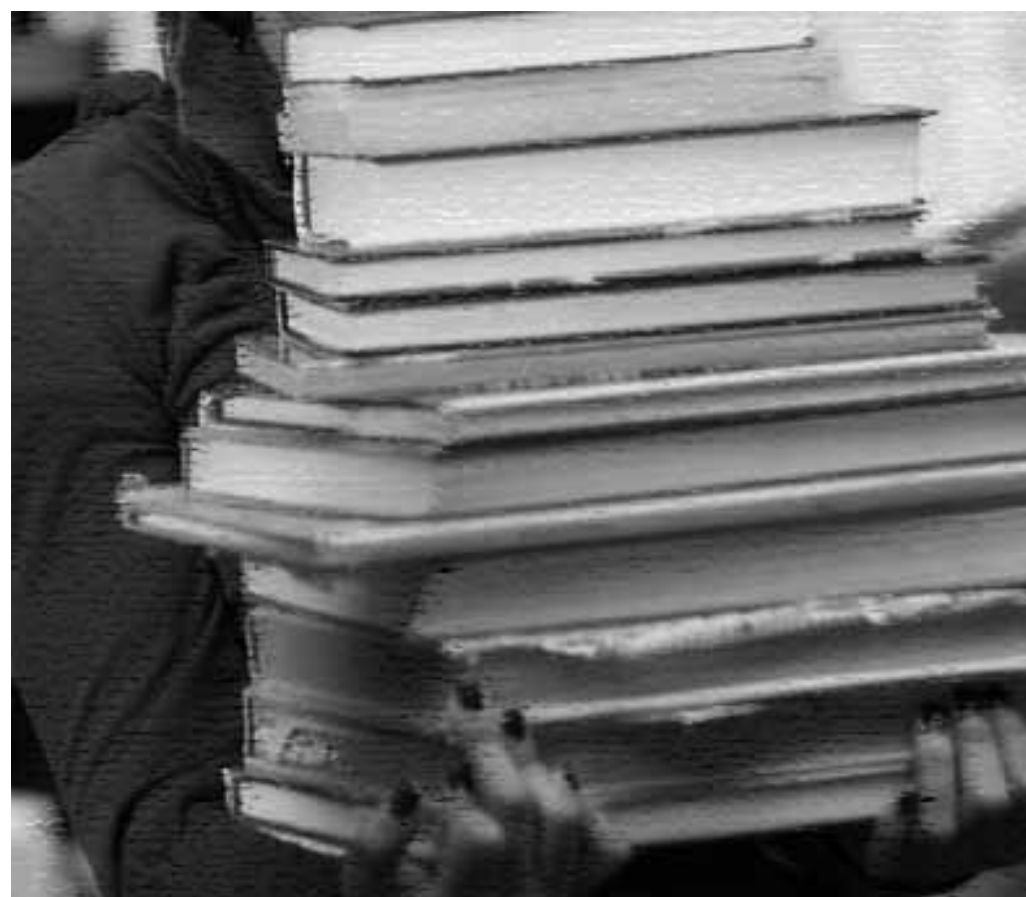


Perguntas de um operário que lê Quem construiu Tebas, a das sete portas?

Nos livros vem o nome dos reis, Mas foram os reis que transportaram as pedras?

(...) Em cada década um grande homem. Quem pagava as despesas? Tantas histórias Quantas perguntas. (Bertolt Brecht, 1982, p. 156)

1Este trabalho foi realizado com bolsa de doutorado do Conselho Nacional de Desenvolvimento Científico e Tecnológico (CNPq) sob orientação da profa. Dra. Marilene Proença Rebello de Souza (IPUSP).

Resumo : Este artigo apresenta alguns dados sobre a história do campo de conhecimento e prática da Psicologia em sua relação com a educação no Brasil. Este estudo foi conduzido baseado no fundamento epistêmico-filosófico do materialismo histórico dialético e na nova história, utilizando fontes bibliográficas históricas e cinco relatos orais de personagens da Psicologia educacional e escolar. Os depoimentos e o material das fontes escritas constituíram o corpus documental, cuja organização seguiu a metodologia da história oral e da historiografia plural. Foi realizada análise descritivo-analítica compreendida em duas etapas: a) análise documental (fontes não orais) e b) construção de indicadores e núcleos de significação dos registros orais. A partir das análises, compôs-se uma periodização da história da Psicologia educacional e escolar brasileira por meio de marcos históricos que compreendeu as fases: 1) colonização, saberes psicológicos e educação (1500-1906), 2) a Psicologia em outros campos de conhecimento (1906-1930), 3) desenvolvimentismo - a Escola Nova e os psicologistas na educação (1930-1962), 4) A Psicologia educacional e a Psicologia do escolar (1962-1981), 5) o período da crítica (1981-1990), 6) a Psicologia educacional e escolar e a reconstrução (1990-2000) e 7) A virada do século: novos rumos? (2000-).

Palavras-chave: Psicologia escolar. Psicologia educacional. História da Psicologia - Brasil.

Abstract: This article presents some data in which the history of the knowledge and practice of educational and school psychology in Brazil was investigated. This study was carried out based on the new history and philosophical-epistemological foundation of historical and dialectical materialism; bibliographical references as well as historical and oral accounts of five living characters of the Brazilian history of Educational and School Psychology were used. The statements of historical sources and the material constituted a corpus of documents whose organization followed the methodology of oral history and pluralistic history. A descriptive analysis was performed in two steps: a) document analysis (non-oral sources) and b) construction of a core of indicators from oral records. From the analysis, a timeline of the history of educational school Brazilian psychology was built through landmarks comprising: 1) colonization, psychological knowledge and education (1500-1906), 2) psychology in other fields of knowledge (1906-1930), 3) "desenvolvimentismo"- the New School and "psicologistas" in education (1930-1962), 4) educational psychology and school psychology (1962-1981), 5) the critics period (1981 - 1990), 6) educational and school psychology and reconstruction (1990-2000), 7) the turn of the century: new directions? (2000- ).

Keywords: Educational psychology. School psychology. Psychology history- Brazil.

Resumen : Este artículo presenta algunos datos sobre la historia del campo de conocimiento y práctica de la Psicología en su relación con la educación en el Brasil. Este estudio fue conducido basado en el fundamento epistémico-filosófico del materialismo histórico dialéctico y en la nueva historia, utilizando fuentes bibliográficas históricas y cinco relatos orales de personajes de la Psicología educacional y escolar. Las declaraciones y el material de las fuentes escritas constituyeron el corpus documental, cuya organización siguió la metodología de la historia oral y de la historiografía plural. Fue realizado un análisis descriptivo-analítico comprendido en dos etapas: a) análisis documental (fuentes no orales) y b) construcción de indicadores y núcleos de significación de los registros orales. A partir de los análisis, se compuso una periodización de la historia de la Psicología educacional y escolar brasileña por medio de marcos históricos que comprendió las fases: 1) colonización, saberes psicológicos y educación (1500-1906), 2) la Psicología en otros campos de conocimiento (1906-1930), 3) desarrollismo - la Escuela Nueva y los psicologistas en la educación (1930-1962), 4) La Psicología educacional y la Psicología del escolar (1962-1981), 5) el período de la crítica (1981-1990), 6) la Psicología educacional y escolar y la reconstrucción (1990-2000) y 7) En el cambio de siglo: inuevos rumbos? (2000- ).

Palabras clave: Psicología escolar. Psicología educacional. Historia de la Psicología- Brasil.

O presente artigo tem como objetivo apresentar alguns resultados oriundos de meu trabalho de doutorado ${ }^{(1)}$ que trata da história da Psicologia educacional e escolar no Brasil e que foi defendido no Programa de Pós-Graduação em Psicologia Escolar e do Desenvolvimento Humano do Instituto de Psicologia da Universidade de São Paulo (IPUSP) (Barbosa, 2011). O estudo teve como objetivo geral realizar um levantamento do histórico da constituição desse campo de conhecimento no interior da Psicologia em nosso país. Como objetivos específicos, buscou-se analisar obras publicadas sobre Psicologia e sua relação com a educação, sobre historiografia da Psicologia e o papel do psicólogo escolar ao longo do tempo. Um diferencial da investigação foi a utilização da história oral como uma das metodologias empregadas. 
Os historiadores são como surdos, dizia Tolstoi, respondem perguntas que ninguém lhes fez (Bosi, 2003, p. 67).
A partir de uma inquietação inicial e de pesquisas preliminares, identificou-se que são muitos os escritos sobre história da Psicologia, porém poucos têm como característica ouvir os próprios partícipes dessa história. Como no poema de Brecht, havia o interesse desta pesquisadora em ir além do que tradicionalmente é descrito, ir também às fontes reais que contribuíram para personificar essa história. Nesse sentido, corroborando a proposição marxista de que a História é feita pelos homens e pelas mulheres que a compõem (Marx, 1888/1977; Marx \& Engels, 1845/2007), esta pesquisa teve como peculiaridade a produção, a organização e a publicidade dos depoimentos de pessoas que viveram parte da história da Psicologia, em especial, personagens da Psicologia educacional e escolar. Assim sendo, foram realizadas gravações de entrevistas orais com cinco pioneiros/protagonistas dessa história, e o resultado dos depoimentos, assim como o levantamento das obras escritas ao longo do século XX, contribuíram para a composição de uma proposta de periodização do histórico dessa área em nosso território.

Essa periodização foi construída a partir da identificação de marcos históricos da área, e compreendeu as etapas: 1) colonização, saberes psicológicos e educação (1500-1906), 2) a Psicologia em outros campos de conhecimento (1906-1930), 3) desenvolvimentismo - a Escola Nova e os psicologistas na educação (1930-1962), 4) a Psicologia educacional e a Psicologia do escolar (1962-1981), 5) o período da crítica (1981-1990), 6) a Psicologia educacional e escolar e a reconstrução (1990-2000) e 7) a virada do século: novos rumos? (2000-). Neste artigo, optou-se por expor o modo de construção da tese no que tange aos processos metodológicos empreendidos e a uma explanação panorâmica sobre cada uma das fases em questão.

\section{O processo de escrita da História - características do trabalho historiográfico}

A História existe independentemente de qualquer escrita; porém, quando se adentra no universo da historiografia, é importante entender que são várias as formas de se narrar uma história, sempre sabedores que não se trata da História propriamente dita e nem da única forma de contá-la. A História (com $h$ maiúsculo), ou conjunto de produções ou transformações empreendidas pela humanidade ao longo do tempo, pode ser descortinada a partir de recortes que os historiadores fazem. Nesse sentido, o que se produz a partir desses recortes são várias histórias (com $h$ minúsculo) que nos fazem compreender fragmentos da realidade por meio dos referenciais escolhidos pelo pesquisador. Portanto, as escolhas que o historiador empreende são de suma importância para delimitar qual será sua contribuição na constituição de uma determinada história.

Geralmente, para balizar esse pensamento, utilizam-se recursos como os recortes temporais, de espaço, de tema e ou de fontes a serem utilizadas. Empregando como exemplo a história da Psicologia, pode se querer estudá-la em um período de tempo específico, os últimos cinquenta anos (recorte temporal), ou a história da Psicologia nos Estados Unidos, no Brasil, em Pernambuco ou em outro lugar (recorte espacial), a história da área de Psicologia do trânsito, da psicoterapia ou da área escolar (recorte temático); e ainda investigá-la a partir de fontes bibliográficas como livros ou revistas científicas produzidas ao longo do tempo ou materiais como documentos históricos e/ou eventos (recorte definido por fontes).

Além desses aspectos, há também a decisão quanto ao modo de apresentação dos dados historiográficos, que podem ser analíticos, 
descritivos, descritivo-analíticos e uma infinidade de outras formas de historiografia, que também passam pelo foco escolhido pelo pesquisador, que pode ou não priorizar os personagens, os locais, as mudanças, o que permaneceu, todos esses aspectos ou outro elemento da história que está sendo investigada. O historiador escolhe em que irá lançar luz ou enfatizar em sua produção. Desse modo, quando se fala em historiografia, há uma gama extensa de possibilidades que se abrem para aquele que deseja realizar um trabalho nesse campo. O ditado popular diz sabiamente que "quem conta um conto, aumenta um ponto", e isso traduz a forma como cada pesquisador pode empreender a narrativa de uma história (que inclusive pode até nem ser uma narrativa). Assim, por trás de toda história, existe aquele que conta a história, e que, portanto, dá a ela o seu matiz, a sua configuração.

Essas considerações têm o intuito de ressaltar que o trabalho aqui apresentado corresponde a uma das possíveis formas de se contar a história da Psicologia educacional e escolar no Brasil. Os resultados exibidos não devem ser encarados como a história dessa área da Psicologia, mas sim, como uma contribuição para a historiografia da Psicologia, especialmente no que se refere à sua relação com a educação em nosso país. A investigação traz, então, as marcas dos recortes feitos ao longo da pesquisa (temáticos, temporais, espaciais e de fontes), assim como as dos matizes escolhidos para serem enfatizados ao longo de sua construção, descritos a seguir.

\section{Apresentando a pesquisa: aspectos teóricos e metodológicos}

Como é sabido, não existe História neutra ou História que seja mera reprodução de fatos ocorridos em determinado momento histórico. (...) Na verdade, o fato histórico é sempre uma escolha do historiador, um recorte feito por ele e que reflete sua subjetividade, seu posicionamento diante do mundo e daquela realidade que está sendo por ele descrita. Não há duas narrativas de um mesmo acontecimento que sejam iguais ou coincidentes. A História é uma construção, construção essa que pode ter maior ou menor compromisso com a evidência, mas na qual existe sempre uma carga indiscutível de subjetividade (Prestes, 2010, p. 91)

Para realizar este estudo, inicialmente, foi escolhido o recorte espacial de circunscrever a investigação à história da Psicologia educacional e escolar no Brasil. Essa escolha deveu-se, sobretudo, à observação de que muitas produções no campo da história da Psicologia privilegiam o enfoque da história dessa ciência a partir de referenciais estrangeiros, especialmente estadunidenses.

Como recorte temático, a prioridade foi a busca pela constituição da Psicologia relacionada à educação, que é muitas vezes nomeada Psicologia educacional e/ou escolar, e que foi, então, conceituada na tese, do ponto de vista histórico, como um campo de conhecimento que tem como foco a relação da Psicologia com a educação. Verificou-se que alguns teóricos denominam esse campo de conhecimento subárea ou subcampo da Psicologia, assim como aparecem as nomenclaturas Psicologia da educação, Psicologia educacional e Psicologia escolar e outras de forma indiscriminada. Optou-se por utilizar o termo área ou campo de conhecimento e a terminologia Psicologia educacional e escolar. A partir da tese, foi possível constatar que, longe de essas diferenças serem apenas denominações correlatas ou formas diferenciadas de nomear o mesmo fenômeno, elas ensejam concepções diversas quanto ao objeto de interesse, às finalidades, aos métodos de investigação e aos conceitos primordiais dessa área ${ }^{(2)}$. Em outras palavras, a opção por uma ou outra denominação tem raízes políticas, sociais, históricas e principalmente ideológicas que marcaram a história dessa área. 
3Os depoentes assinaram Termo de Consentimento Livre e Esclarecido para realização da pesquisa e também um Termo de Autorização Livre e Esclarecido para uso do depoimento.

Ambos os termos compreendem a afirmação de que seus nomes não seriam omitidos na citação de seus depoimentos. Eles concordaram com a exposição de suas identidades, bem como autorizaram a publicação dos depoimentos (que foram revisados pelos mesmos) e que estão na íntegra na tese.

4 A primeira lista de possíveis depoentes compreendia entrevistas com vários outros pioneiros ou protagonistas contudo, devido ao tempo exíguo do doutorado, não foi possível realizá-las. Isso não causou prejuízo aos objetivos do trabalho dado a riqueza de detalhes, informações e abrangência dos depoimentos realizados.
A partir dessas considerações, a Psicologia educacional e escolar é aqui entendida como um campo de conhecimento ou área da Psicologia cujo compromisso é a relação com a educação. Corroboramos a definição de Tanamachi e Meira, que afirmam que esse campo é uma "(...) área de estudo da Psicologia e de atuação/ formação profissional do psicólogo, que tem no contexto educacional - escolar ou extra-escolar, mas a ele relacionado-, o foco de sua atenção (...)" (Tanamachi \& Meira, 2000, p. 11). Também como as autoras asseveram, o profissional identificado com essa área, mesmo que não atue diretamente no contexto escolar, tem um compromisso teórico e prático com as questões da escola e da educação como um todo. Ao estudar ou produzir referências (ciência) ou atuar (profissão) nesse campo, não deve limitar-se aos conhecimentos nem da Psicologia, nem da educação, nem de outro campo, mas utilizar como base as inúmeras e fecundas produções de outras áreas que também contribuem para pensar sobre as questões educativas como a Filosofia, a Sociologia, a Antropologia, etc. Em resumo, a Psicologia educacional e escolar é um campo de conhecimento que abarca as dimensões teóricas e práticas e, sobretudo, práxicas de compromisso ético político com as questões educacionais, escolares e com a sua melhoria, utilizando-se das interfaces de conhecimentos produzidos pelas ciências humanas.

Como recorte temporal da tese, escolheu-se inicialmente o período pós-profissionalização, que principia com a criação da profissão de psicólogo, em 1962. Porém, no decorrer da construção da pesquisa, optou-se pela ampliação do período em questão para abarcar os primeiros conhecimentos oriundos da relação Psicologia e educação que podem ser identificados no período colonial através dos relatos da educação jesuítica. Os dados construídos permitiram um avanço até os anos 2000, de modo que, mesmo sucintamente, são apontados os marcos históricos de cada período compreendido nesse espaço temporal.

Quanto às fontes, a partir da metodologia da história oral, priorizou-se encontrar pessoas que pudessem dar depoimentos sobre a sua participação na constituição da história da Psicologia educacional e escolar no Brasil. Foram selecionados alguns critérios para a escolha desses testemunhos que deveriam ter, sobretudo, o caráter de pioneiros ou de protagonistas na área. Além disso, cada depoimento deveria abarcar, na medida do possível, um período específico dessa história, ou de acontecimentos marcantes, de modo a mapear o tempo estudado em questão. Nesse sentido, os cinco participantes foram escolhidos por terem: a) realizado publicações expressivas na área, b) atuado na área, c) sido docentes; e/ou d) participado de órgãos/instituições da área. Os depoentes foram os professores Doutores Samuel Pfromm Netto, Geraldina Porto Witter, Arrigo Leonardo Angelini, Raquel Souza Lobo Guzzo e Maria Helena Souza Patto(3). Cada um desses depoimentos foi gravado, transcrito e transcriado a partir do que foi indicado por Meihy (2000). Os entrevistados puderam conferir seus testemunhos e revisá-los, o que se transformou na versão final que foi exposta na íntegra na tese ${ }^{(4)}$.

Além dos depoimentos orais, serviram como fontes documentos escritos, visitas a centros de documentação e História e, especialmente, obras com temas que se relacionam à Psicologia educacional e escolar cuja escolha se deu por serem representativas de determinado período histórico. A busca por essas referências também priorizou conhecer os personagens que marcaram essa história, inclusive aqueles falecidos, além de buscar abranger referenciais de várias partes do Brasil, não se limitando a um determinado Estado da Federação. Essa preocupação se 
Resgatar 0 passado tal como se deu na sua totalidade não é completamente possível, nem é tarefa que consiga chegar a ser um produto acabado"

(Antunes, 1996, p. 95). deveu, sobretudo, ao fato de os depoentes terem atuado sobretudo no Estado de São Paulo e terem participado do período da profissionalização. As referências escritas e os diários de campo das visitas cumpriram, assim, o papel de cobrir informações de tempos longínquos, de personagens falecidos e de fornecer elementos sobre a Psicologia educacional e escolar em alguns dos Estados do território nacional.

Feitos os recortes espacial, temático, temporal e de fontes, foi possível a construção de um corpus documental que foi interpretado de forma descritivo-analítica com base nos pressupostos da nova história e do materialismo histórico e dialético. Como foram utilizados vários referenciais para orientar o trabalho, bem como diferentes tipos de fontes, análises e formas de apresentação dos resultados, entendeu-se que se poderia denominar a metodologia principal como sendo a história pluralista ou a abordagem plural, esta coaduna diferentes possibilidades de configuração no campo da historiografia.

De modo geral, o processo de análise dos resultados foi organizado da seguinte maneira: cada depoimento e fonte foi analisado em separado e em conjunto, inter-relacionando ao corpus documental. As análises e a discussão dos resultados compreenderam duas etapas: (a) análise documental (fontes não orais) e (b) construção de indicadores e núcleos de significação dos registros orais. Para instrumentalizar esse processo, foram utilizadas as referências de análise de conteúdo de Bardin (1995), de análise documental de Pimentel (2001), e de análise e construção de indicadores e núcleos de significação de Aguiar e Ozella (2006). Além destas, foram de suma importância para nortear todo o processo de construção e discussão dos dados as orientações quanto à produção historiográfica de Marx e Engels (1847/1977, 1845/2007), Hobsbawm (1998), Paulo Netto (1998), e, especificamente, sobre história oral, as referências de Meihy (2000), Thompson (2002) e Portelli (1997).

Após as etapas a) e b) de interpretação dos elementos construídos a partir do corpus documental, procurou-se reunir esses fragmentos em uma narrativa descritivoanalítica de forma a articular os depoimentos e as fontes escritas. Foi através dessa articulação (triangulação) dos elementos investigados que se construiu uma proposta de periodização da história da Psicologia educacional e escolar no Brasil que abrange as sete fases ou etapas anteriormente citadas e que serão melhor explicitadas a seguir.

\section{Para uma história da Psicologia educacional e escolar no Brasil}

\begin{abstract}
Resgatar o passado tal como se deu na sua totalidade não é completamente possível, nem é tarefa que consiga chegar a ser um produto acabado. Deve-se procurar, no entanto, juntar os elementos disponíveis, organizá-los, buscando compreender suas contradições e a dinâmica de seu movimento e, fundamentalmente, tentar, com a limitação inerente ao olhar do presente, mais se aproximar do passado e compreendê-lo a partir dos sinais que permaneceram. Melhor compreendendo o passado e seu processo de construção, certamente se tornará mais límpida a compreensão do presente, no qual o passado se encontra como uma determinação e base de sustentação (Antunes, 1996, p. 95)
\end{abstract}

Quando se fala que a Psicologia está fazendo cinquenta anos no Brasil, é porque está se usando como marco inicial a legislação de criação da profissão de psicólogo, a Lei no 4.119, que foi aprovada em 27 de agosto de 1962 (Brasil, 1962). Também por isso se comemora o Dia do Psicólogo em 27 de agosto. Além dessa lei, é importante destacar a Resolução de 19 de dezembro de 1962, que estabeleceu o currículo mínimo para os cursos de formação de psicólogos (Brasil, 1962), e o Decreto no. 53.464, de 21 de janeiro de 1964, que regulamentou a Lei no. 
4.119 (Brasil, 1964). Esse decreto descreve as funções desse profissional bem como as características do seu exercício profissional e formação. O Conselho Federal de Psicologia (CFP), por sua vez, foi criado pelo Decreto no. 79.822, de 17 de julho de 1977 (Brasil, 1977), e, na sequência, foram criados os Conselhos Regionais.

Essas delimitações legislativas que marcam a história da Psicologia contam especificamente do processo de profissionalização, pois os saberes da Psicologia e mesmo algumas práticas têm origens anteriores. Se, como fazem os historiadores estrangeiros da Psicologia, fôssemos considerar como marco inicial a criação do primeiro laboratório, a exemplo do laboratório criado por Wundt em $1875^{(5)}$ em Leipzig na Alemanha, teríamos outra data de comemoração. O primeiro laboratório brasileiro foi instituído em 1906, no Rio de Janeiro (Penna, 1985; Antunes, 2001; Centofanti, 2006) no interior do Pedagogium, instituição criada como museu pedagógico, e ficou a cargo de Manoel Bomfim. Esse estabelecimento de datas se complica um pouco, porque o próprio Pedagogium foi instituído antes em 1890, e em sua origem, no Decreto no. 981, de 8 de novembro de 1890, Regulamento da Instrucção Primária e Secundária do Districto Federal, já se pressupunha a existência de laboratórios práticos, o que se efetivou posteriormente (Brasil, 1890).

5 A data da criação do Laboratório de Psicologia Experimental na Universidade de Leipzig, na Alemanha, criado por Wundt é

referida por alguns historiadores da Psicologia como tendo ocorrido em 1875 , e, por outros, em 1879 (Ver:

Shcultz \& Schultz, 2002; Araújo, 2007; Figueiredo \& Santi, 2004; Goodwin,
Bonfim, que funcionou até 1919, quando foi extinto.

Em 1909, Clemente Quaglio criou também um gabinete de Psicologia Experimental no Grupo Escolar de Amparo em São Paulo, e, posteriormente, contribuiu com Ugo Pizzoli para a instalação do Laboratório de Psicologia na Escola Normal da Praça da República, em São Paulo. Conforme Antunes (2001) e Waeny e Azevedo (2009), foi na gestão de Oscar Thompson, então diretor da Escola Normal de São Paulo, que foi contratado o italiano Ugo Pizzoli, catedrático da Universidade de Modena, na Itália, como responsável por organizar o laboratório. Esse laboratório, após o de Bonfim, foi um dos principais centros de produção de estudos e de pesquisas psicológicas ainda em um tempo em que não havia a profissão de psicólogo no Brasil; também contribuiu para formar profissionais que, em sua maioria, atuariam com Psicologia no ensino das Escolas Normais. É por essa razão que Pfromm Netto (1996) chama a primeira fase da Psicologia educacional brasileira de fase normalista. Esse autor realizou importante contribuição para a historiografia da Psicologia educacional e escolar no Brasil a partir do texto As origens e o Desenvolvimento da Psicologia Escolar (Pfromm Netto, 1996). Em sua análise, a Psicologia escolar passa por três fases: a primeira, entre 1830 e 1940, que denominou período normalista, a segunda, entre 1940 a 1962, corresponde à fase universitária, e a terceira fase inicia-se com o ensino de Psicologia escolar na graduação em Psicologia, a partir da criação da profissão de psicólogo, em 1962.

O referencial usado pelo autor supracitado é balizado por marcos da institucionalização da Psicologia, seja via Escola Normal, universidade ou graduação de psicólogos. Caso quiséssemos determinar o período inicial da Psicologia com base na criação dos primeiros cursos de formação de psicólogos, teríamos então outros referenciais, como a organização de um curso 
em 1932, no Laboratório de Psicologia da Colônia de Psicopatas de Engenho de Dentro, no Rio de Janeiro, coordenado por Waclaw Radecki. Esse psicólogo polonês propôs a transformação desse laboratório em Instituto de Psicologia e passou a oferecer um curso de formação em Psicologia. Entretanto, após sete meses de funcionamento, o curso foi fechado por várias razões (Centofanti, 1982).

Sabe-se que Radecki havia sido colaborador de Claparède e diretor do Laboratório de Psicologia da Universidade Livre da Cracóvia, e que o curso projetado por ele teria duração de seis meses, com disciplinas como Metodologia do Trabalho Experimental em Psicologia e Problemas Fundamentais do Psicopedagogo, entre outras. Caso tivesse sido levada adiante, essa seria uma primeira experiência em termos de formação em Psicologia ainda nos anos 30, inclusive com nuances de ensino de Psicologia educacional e escolar.

Helena Antipoff também organizou, no Laboratório de Psicologia da Escola de Aperfeiçoamento de Professores de Belo Horizonte, em Minas Gerais, cursos para divulgação de conhecimentos psicológicos trazendo psicólogos estrangeiros, como Leon Walther e Theodore Simon, para minisrtrálos. Alguns cursos foram ministrados nos anos 50 com características de especialização para graduados; essa iniciativa merece relevo primeiro, por ser uma formação especializada, e segundo, porque ainda não estava estruturada a profissão de psicólogo, nem as graduações em Psicologia no País, muito menos as pós-graduações. Esses cursos foram importantes espaços de formação nesse sentido. Um outro exemplo se deu em 1956: o Instituto Superior de Educação Rural - ISER, na Fazenda do Rosário, em Ibirité (Minas Gerais), por iniciativa de Antipoff, organizou um curso do professor André Rey de Psicologia experimental, cujo conteúdo abordou a avaliação de crianças e adultos e o ensino de Psicologia em Cursos Normais (Clio-Psyché, 2010).

Assim eram formados os chamados psicologistas, que foram os primeiros profissionais a praticar a Psicologia no Brasil até que aqui pudesse se formar psicólogos, algo que ocorreu somente após a regulamentação da profissão (Bernardes, 2004). A Universidade de São Paulo também contribuiu para a formação desses primeiros profissionais graças a cursos criados nas cátedras de Psicologia e de Psicologia Educacional da Faculdade de Filosofia, Ciências e Letras (FFCL). Em 1945, foram criados cursos de Psicopatologia e de Psicologia Clínica, por iniciativa de Annita Cabral, na cátedra de Psicologia. Em 1947, por ação de Noemy da Silveira Rudolfer, a cátedra de Psicologia Educacional ofereceu um curso de Psicologia Educacional (depoimento de Arrigo Angelini para Barbosa, 2011).

Esse panorama oferece um emaranhado de construções paralelas e diferenciadas que contribuíram para erigir a Psicologia brasileira. E complica-se mais um pouco, ao pensarmos que, além dessas referências, que dizem respeito à institucionalização e à profissionalização da Psicologia, devemos recuar um pouco mais no tempo e encontrar contribuições anteriores a essas, como nos têm mostrado os estudos de Massimi (1984, 1990) e Massimi e Guedes (2004) sobre os saberes psicológicos desde o tempo do Brasil-colônia.

Nesse sentido, é necessário que o pesquisador em História esteja certo de quais serão os recortes e as delimitações que irão balizar seus estudos, de modo a poder realizar uma contribuição para a historiografia da Psicologia que considere essa diversidade. Além disso, é necessária uma bússola que oriente suas investigações, que possa determinar o que irá focalizar, assim como e de que forma irá poder descortinar esse conjunto imenso de informacões multifacetadas. 
Para a construção do meu trabalho de doutorado, que buscou compreender a história da Psicologia educacional e escolar, utilizei como referencial basilar a divisão organizada por Antunes (1991, 2001) quanto à história da Psicologia no Brasil. A autora a divide em cinco períodos: 1) pré-institucional (período colonial), 2) institucional (século XIX), 3) autonomização (1890-1930), 4) consolidação (1930-1962) e 5) profissionalização (1962 em diante).

No primeiro período, a Psicologia é compreendida como saberes constituídos que eram disseminados, elaborados e utilizados no interior de outras áreas de conhecimento. Segundo Antunes (1991, 2001), há uma dupla origem da Psicologia brasileira que se estabelece a partir dos conhecimentos médicos e educacionais. No período colonial, são constituídos conhecimentos psicológicos no interior da educação jesuítica, e também estes aparecem posteriormente no tratamento de doenças mentais no campo psiquiátrico.

No século XIX, período denominado pela autora de institucional, principiam as primeiras publicações científicas nos cursos superiores das faculdades de Direito e de Medicina. Uma dessas primeiras teses, intitulada Paixões e Afetos da Alma, de M. I. Figueiredo Jaime, defendida na Faculdade de Medicina no Rio de Janeiro, em 1836 (ver Pfromm Netto, 1979), cuja temática envolvia assuntos psicológicos. Além disso, foi no século XIX que se construíram as primeiras teorizações (ciência) que tinham como tema as práticas higiênicas que envolviam os conhecimentos de Psicologia, medicina e educação, e também a entrada da Psicologia nos cursos de formação de professores através do ensino nas Escolas Normais.

O período que Antunes denomina autonomização (1890-1930) corresponde à constituição da autonomia da Psicologia em relação aos outros campos de saberes e atuação. A Psicologia passa a produzir seus próprios conhecimentos e a se erigir como um conhecimento autônomo com objeto específico, métodos e técnicas específicas e também modos diferenciados de atuação. Data desse momento a criação, em âmbito internacional, dos laboratórios de Psicologia no interior de universidades, assim como no Brasil inicia-se processo semelhante, como dito anteriormente sobre os laboratórios do Pedagogium, da Escola Normal de São Paulo e outros símiles.

A fase descrita por Antunes (1991, 2001) como consolidação (1930-1962) é a etapa da construção das primeiras associações de Psicologia, como a Sociedade Brasileira de Psicologia de São Paulo (1945), a Associação Brasileira de Psicotécnica (1950), a criação das primeiras revistas científicas e dos primeiros cursos de formação de psicologistas. Nesse momento, principia em grande parte a aplicabilidade da Psicologia em vários campos, como a clínica, os processos organizacionais, do trabalho e também educacionais. É quando há uma consolidação dos saberes e das práticas dessa ciência autônoma, que prepara, então, o terreno para a criação da profissão de psicólogo no País.

A fase subsequente inicia-se com a criação da lei que regulamenta a profissão de psicólogo no Brasil, a partir de 1962, e é denominada período da profissionalização (1962- em diante).

Na mesma linha de raciocínio, Antunes (2003, 2008, 2011) escreve sobre a história da relação entre a Psicologia e a educação. A autora destaca, por exemplo, como, ao longo do tempo, essa área de conhecimento da Psicologia passou por transformações, sendo inicialmente vinculada a um ideário normativo e classificatório, oriundo dos movimentos 
Antunes (2003, 2008) destaca que a Psicologia educacional e escolar é fundante da própria Psicologia no Brasil, pois foi através especialmente dos primeiros psicologistas da educação que a Psicologia foi consolidando-se como ciência e profissão. de testes no interior dos laboratórios das Escolas Normais, procurando articular-se à consolidação dos propósitos capitalistas e do Brasil industrial. Posteriormente, veio a se reconfigurar a partir das críticas a esse tipo de orientação, através da prática profissional em escolas com vertentes ora clínicas, ora educativas (Taverna, 2003).

Antunes (2003, 2008) destaca que a Psicologia educacional e escolar é fundante da própria Psicologia no Brasil, pois foi através especialmente dos primeiros psicologistas da educação que a Psicologia foi consolidandose como ciência e profissão. Em sua opinião, nos últimos anos do século XX, essa área da Psicologia ampliou e explicitou seu compromisso social, contribuindo para práticas de cunho emancipatório no interior das políticas públicas educacionais (Antunes, 2006, 2011).

E foi a partir desses apontamentos que pude, a partir do estudo que realizei no doutorado (Barbosa, 2011), articular as fontes escritas e orais e propor uma periodização específica de constituição da história da Psicologia educacional e escolar que compreendesse as seguintes etapas: 1) colonização, saberes psicológicos e educação - educando meninos rudes (1500-1906), 2) a Psicologia em outros campos de conhecimento (1906-1930), 3) desenvolvimentismo - a Escola Nova e os psicologistas na educação (1930-1962), 4) a Psicologia educacional e a Psicologia do escolar (1962-1981), 5) o período da crítica (1981-1990), 6) a Psicologia educacional e escolar e a reconstrução (1990-2000) e 7) a virada do século: novos rumos? (2000- ). Conforme apontado anteriormente, essa construção foi possível graças à articulação dos elementos obtidos através das fontes orais e também escritas.

O primeiro período: colonização, saberes psicológicos e educação (1500-1906), tem como marco inicial a chegada dos portugueses no Brasil e especialmente o início da missão jesuíta em 1549. Os jesuítas construíram, pela primeira vez nesta terra, um sistema educativo para catequização dos índios. Esse ensino incluía os ensinamentos bíblicos e também o ensino de português e das operações matemáticas elementares. Foram criados colégios para ensinar "a ler e a escrever" e assim como afirma Massimi (1984, 1990 e 1997), pode-se encontrar nuances de ideias psicológicas nessa educação inicial.

Antunes (2003) afirma que, no período, o propósito de aplicação de conhecimentos psicológicos tinha como prerrogativa a educação do comportamento, de modo a domar e a moldar as crianças, com a utilização de prêmios e de castigos para educar. A autora nos conta que Manoel Andrade de Figueiredo falava da "educação dos meninos rudes" que deveria, por outro lado, ser ausente de castigos. Encontram-se no período obras que ressaltam o papel da educação moral, física e fórmulas de como melhor educar os filhos.

Nesses primórdios, podemos falar apenas em saberes psicológicos disseminados no interior da educação jesuíta, ainda fortemente alicerçados ao propósito da colonização. A influência do pensamento empirista e das teorizações existentes sobre domesticação por meio de castigos e de prêmios é uma das marcas dessa fase.

Com a criação, em 1906, do primeiro laboratório no interior do Pedagogium, conforme dito anteriormente, inaugura-se um novo momento: a Psicologia em outros campos de conhecimento (1906-1930). A Psicologia educacional (que ainda não carrega o título de escolar e que, por vezes, é denominada educacional), nesta fase é inserida em currículos das Escolas Normais. É um momento em que há uma exigência de cientifização da educação, e uma das ciências que vem dar respaldo à educação e à Pedagogia é a ciência psicológica. 
Segundo Waeny e Azevedo (2009), data desse período a introdução da disciplina Psicologia e Lógica e Pedagogia e Lógica nos cursos das Escolas Normais com vistas a disseminar os conhecimentos da Psicologia que pudessem contribuir para os processos educativos. Nota-se ainda a forte influência do pensamento empirista, porém, nesse momento, surgem novas contribuições de pesquisas que eram aplicadas no exterior, especialmente ligadas à Psicologia infantil, à Psicologia aplicada e o que se denominava Pedagogia científica ou ainda Pedagogia terapêutica e Psicologia pedagógica. Estas tinham como principais contribuições criticar o processo educativo centrado unicamente no papel do professor (educação tradicional) e trazer à cena a importância de se conhecer os processos de desenvolvimento do educando, o que veio a ter seu auge a partir dos anos 1930.

No início do século XX, grandes transformações ocorreram nesse campo; a Psicologia escolar e educacional também estava nascendo em termos acadêmicos internacionalmente, pois tem-se como marco inicial a publicação de Thorndike intitulada Educational Psychology, em 1903, que também colabora para a criação da primeira revista dessa temática nos Estados Unidos, intitulada Journal of Educational Psychology, em 1910. Além disso, principiam contribuições de vários pesquisadores, em diferentes países, que passam a publicar temas relacionando Psicologia e educação. Pfromm Netto (1996) cita como importantes para a área os trabalhos de Stanley Hall e Lightner Witmer (EUA), Galton, Sully, Burt (Inglaterra), Decroly (Bélgica) e Ebbinghaus (Alemanha), entre outros. Nesse período, crescem os estudos sobre aprendizagem, desenvolvimento, processos cognitivos e testes psicológicos (psicometria), assim como sobre as relações entre os conhecimentos psicológicos e seu papel no processo de ensino.
O terceiro período: desenvolvimentismo - a Escola Nova e os psicologistas na Educação (1930-1962), foi especialmente profícuo para a Psicologia educacional e escolar. Essa fase foi tão importante que Samuel Pfromm Netto afirma, em seu depoimento para a tese (Pfromm Netto em Barbosa, 2011, p. 480): “(...) Devem datar dos anos trinta, da década de trinta (1930), os primeiros vagidos da Psicologia escolar no Brasil, perdão, Psicologia educacional, pois não se falava de Psicologia escolar naqueles tempos...". Como se verificará a seguir foi nessa época que se erigiu boa parte do que posteriormente veio a se constituir na área que estamos aqui enfocando.

Graças ao movimento internacional da Psicologia aplicada e à influência de psicólogos estrangeiros que vieram para o Brasil e iniciaram a formação e a disseminação dos conhecimentos psicológicos, podemos dizer que é a primeira vez que temos uma Psicologia que se efetiva em termos práticos no interior de organizações como hospitais, organizações industriais e, especialmente, escolas. A denominação desenvolvimentismo foi escolhida por marcar além do momento histórico social que o Brasil estava vivendo, em termos de incremento e de crescimento vertiginosos da economia e produção industrial, e por também estar relacionada ao grande crescimento da Psicologia em vários campos teóricos e práticos. O movimento da Escola Nova também é característica do momento.

Os anos 30 (do século XX) começam atribulados devido a grandes transformações políticas, econômicas e sociais, e, no campo educativo, temos a reivindicação de vários educadores que se auto-denominaram pioneiros da Educação Nova e que, por meio do Manifesto dos Pioneiros da Educação Nova (1932) solicitavam ao poder público uma renovação do campo educativo. O 
Brasil, a essa época, tinha alto índice de analfabetismo e um sistema educativo mal estruturado, e poucos tinham acesso à escola. Esse quadro inspirou o clamor por mudanças, o que trouxe várias modificações nesse campo.

Patto (1981) descreve as principais transformações ocorridas no período: 1) eram exigidas reformas educacionais para atingir a maior parte da população, porém de forma populista, pois o povo não participava das decisões, 2) foi criado o Ministério da Educação, 3) o ensino organizou-se nos moldes como conhecemos hoje: primário, secundário e superior, através da Reforma Francisco Campos, 4) a Reforma Francisco Campos estabeleceu o Estatuto das Universidades, abrindo possibilidade para a criação de universidades, 5) foi criada a Universidade de São Paulo e outras na sequência, 6) foi elaborada a Constituição de 1937, que regulamentou as escolas técnicas (SENAI, SENAC) e o ensino vocacional e 7) estabeleceu-se a Reforma Capanema, de 1942, que reorganizou o ensino secundário dividindo-o em ciclos, primeiro, o ginasial, e segundo, o clássico ou científico.

O Manifesto dos Pioneiros da Educação Nova foi um documento que exigia dos poderes públicos educação laica, gratuita e obrigatória para toda a população em idade escolar baseado nos pressupostos escolanovistas. No próprio texto do Manifesto, nota-se a influência dos conhecimentos psicológicos oriundos das produções em Psicologia infantil e do ideário da Escola Nova. O escolanovismo tinha como prerrogativa a descentralização do ensino da figura do professor e a ideia de uma escola mais ativa, que pudesse colocar o educando em foco e proporcionar atividades práticas que o levassem a aprender de modo mais dinâmico.
É importante destacar que muito do que se produziu inicialmente no Brasil, nessa época, especialmente nos laboratórios de Psicologia das Escolas Normais, teve muita influência dos trabalhos de Claparède e de sua Psicologia pedagógica e das produções do Instituto Jean-Jacques Rousseau. Esse instituto era referência em pesquisa e formação, e sua produção passou a influenciar a construção de ideias nesse campo em relação às teorizações que hoje denominamos campo da Psicologia educacional e escolar. Nos dizeres de Cambi (1999), foi o período do movimento do "puericentrismo pedagógico".

É ainda destaque nesta fase o crescimento das ideias sobre educação especial e influência da psicanálise e das contribuições estadunidenses no interior da Psicologia naquele momento denominada de Psicologia educacional. É flagrante a consolidação no período da ideia de foco no aluno, com estudos realizados seja pelas vias psicométricas, seja psicoanalíticas. Havia também um interesse em classificar e encontrar formas de educar aqueles que eram chamados de desajustados, ou desviantes, considerados então anormais.

Se antes podíamos dizer que a Psicologia educacional e escolar estava disseminada em outros campos de conhecimento, ainda não de maneira autônoma, a partir dos anos 30, esse quadro se altera. Essa área ainda chamada de Psicologia educacional foi se estabelecendo como campo de saber com objeto de estudo, linhas de pesquisa e atuação específicos identificados por esse olhar para a criança que não aprende. Os processos de desenvolvimento e de aprendizagem passam a constituir elementos prioritários de análise, e a Psicologia infantil, a Psicologia diferencial e Psicologia pedagógica situamse como referências, mantendo a ênfase na criança. No caso dos processos educativos, observa-se o crescimento do movimento de identificação, testagem e classificação das 
crianças, com o intuito de conhecer suas habilidades e problemas. É o momento da separação das crianças ditas normais daquelas com problemas de aprendizagem, também chamadas de anormais, deficientes, anormaes de escola, crianças-problema (Ver: Pettirossi \& Lombardi, 1997; Cotrin, 2010).

Assim, pode-se afirmar que a Psicologia educacional e escolar se erigiu, em termos práticos, do movimento oriundo desses pressupostos teóricos e práticos que aliava Psicologia pedagógica, infantil e Escola Nova, e do avanço da onda dos testes e orientações clínicas infantis das criançasproblema. O pensamento higienista e também o eugenista aparecem como influências iniciais, o que justificava a identificação, a seleção e a classificação das crianças.

Datam da década de 30 também os primeiros trabalhos nos parques infantis da cidade de São Paulo (Taverna, 2003), que foram o berço dos serviços que depois se organizaram em clínicas de atendimento infantil e que deram origem posteriormente ao trabalho de Psicologia escolar no Município. Também foi no período que surgiu o Serviço de Saúde Escolar, organizado por Durval Marcondes na capital paulista, cuja perspectiva era o atendimento clínico educacional com base psicanalítica. Como se pode notar, o início do desenvolvimento da área no Brasil se deu a partir da constituição do seu campo de interesse, foco e atuação, especificamente com vistas ao ajustamento, disciplinarização e normatização, pois o enfoque inicial era a identificação e o tratamento das crianças ditas desviantes. Também a chamada educação especial foi um campo fértil em cujas bases se assentou essa Psicologia educacional e escolar principiante, como também o foi o campo da orientação profissional. É importante destacar, ainda, que os psicologistas que atuavam nesses primórdios tinham como características essas múltiplas influências, portanto, suas práticas eram construídas de várias formas, a partir, por exemplo, dos testes, da clínica psicanalítica, do pensamento higienista, eugenista, da Psicologia infantil empirista e da orientação profissional.

A criação da Universidade de São Paulo também terá grande influência, pois, na Faculdade de Filosofia, Ciências e Letras (hoje Faculdade de Filosofia, Letras e Ciências Humanas - FFLCH da USP), instituem-se as cátedras de Psicologia e de Psicologia educacional, que foram a origem das instituições formadoras posteriores, como a graduação em Psicologia no Instituto de Psicologia da USP nos anos 70. Também o mestrado em Psicologia escolar é estruturado em 1970, nessa mesma instituição (Schmidt, Sekkel, Souza, Barbosa, \& Santos, 2010).

Para Patto, a Psicologia educacional e escolar nasce alicerçada aos interesses políticos, sociais e econômicos do sistema capitalista, e as teorias que passam a alimentar os trabalhos dos psicólogos dessa área trazem como pressuposto o ideário liberal de que a escola é uma instituição que promove igualdade e oportunidades, ideologia que mascara a desigualdade e a injustiça social desse sistema. Ela afirma que o movimento dos testes, que tem início nos anos que antecedem a profissionalização e seguem crescendo até meados dos anos 80 , denotam esse interesse ideológico:

É por aí que a história da presença da Psicologia na educação começa. Começa medindo aptidões tidas como naturais, e tentando fazer um encaixe perfeito entre as capacidades medidas de Q.I., habilidades específicas etc., e o ensino. Era o raciocínio muito parecido com o da taylorização do processo de produção industrial. (...) Houve um namoro sério da Escola Nova com o taylorismo, tanto lá fora como aqui no Brasil. E essa ideia do ajustamento, digamos assim, entre o processo de ensino 
e as características do aprendiz (Patto em depoimento a Barbosa, 2011, p. 644)

Essa é a base da educação compensatória, que tem como intuito cobrir as ditas falhas trazidas pelo educando, que contribuiu para colocar a Psicologia no lugar de ciência que pode contribuir com "o escolar" de forma classificatória e discriminatória. Com isso, erguem-se as bases para a transformação da Psicologia educacional em Psicologia "do" escolar, algo que se consolida no próximo período após a profissionalização.

Em 1962, como dito antes, é criada a profissão de psicólogo no Brasil, e iniciase a fase da Psicologia educacional e da Psicologia "do" escolar (1962-1981). Dando continuidade a todo o desenvolvimento do período anterior, ao se criar os cursos de Psicologia, as múltiplas influências de formação e de atuação se fizeram permanentes. A Psicologia, em sua relação com a educação, continuou então a fazer o trabalho de classificar, orientar e tratar de crianças-problema, com o interesse de se posicionar a favor do escolar. $\mathrm{O}$ foco individual de orientação é a marca da área nesse momento, e inicia-se a produção de laudos de crianças em idade escolar para encaminhamento às chamadas escolas especiais e depois às classes especiais.

A ditadura militar de alguma forma contribuiu para o recrudescimento de algumas práticas e de construção de saberes na Psicologia. Muitos profissionais sofrem perseguições, cursos são fechados e há relatos de demissões de professores considerados subversivos. Por outro lado, também existiram aqueles que contribuíram para o regime, inclusive profissionais ligados ao corpo militar. Na tese, alguns dos depoentes falam desse período e da cisão entre aqueles que contribuíam e outros que combatiam as atrocidades do regime militar, pois, segundo Guzzo, houve psicólogos de ambos os lados: “(...) Teve uma cisão ali... os psicólogos que ficaram de um lado e os que ficaram do outro, as instituições que ficaram de um lado e as que ficaram do outro..." (Guzzo em depoimento a Barbosa, 2011). No que se refere à Psicologia educacional e escolar, é digno de nota o fechamento das escolas experimentais em São Paulo, assim como o dos ginásios vocacionais, que tinham um trabalho pioneiro que envolvia a participação de psicologistas e educadores.

Nos anos 70, vemos emergir a influência das teorias behavioristas e da chamada tecnologia educacional, que se traduziu, em termos pedagógicos, no ensino tecnicista. Além disso, mantém-se o interesse voltado para os estudos do escolar, sendo que cresce a chamada teoria da carência cultural como explicação para o não aprender das crianças na escola. Essa teoria nascida nos Estados Unidos era:

Fruto dos movimentos reivindicatórios das minorias negras e de imigrantes latinos que apresentavam baixo rendimento escolar, essa teoria procurava responder à pergunta: por que um grande contingente de crianças negras e imigrantes não aprendia na escola pública americana? Para responder essa questão, psicólogos e demais profissionais passaram a pesquisar as causas dos problemas de aprendizagem, buscando-as nos aspectos do desenvolvimento infantil, nas áreas de nutrição, linguagem, estimulação, cognição, inteligência, motricidade etc. Ocorre, porém, que os resultados dos experimentos realizados por tais crianças eram comparados com aqueles obtidos com crianças de classes média e alta da sociedade americana, branca e empregada. Tais resultados eram considerados como padrão de normalidade (Souza, 2002, p. 177)

A teoria da carência cultural passa a ser principal explicação para o não aprender na escola, e principiam programas educacionais de educação compensatória. É nesse período que se inicia o crescimento da oferta de serviços de Psicologia escolar em âmbitos como secretarias municipais de Educação que, em grande 
parte, tinham como prerrogativa o trabalho psicométrico e/ou de tratamento clínico dos chamados problemas de aprendizagem. O exame do que estava sendo oferecido nesses serviços, bem como uma análise crítica dos referenciais psicometristas, da teoria da carência cultural e de abordagens clínicas na escola, faz surgir a próxima etapa.

Maria Helena Souza Patto revela, em seu depoimento para a tese (Barbosa, 2011) que, quando assumiu a disciplina Psicologia "do" Escolar na graduação do Instituto de Psicologia da USP, retirou o "do", ficando a disciplina sendo chamada de Psicologia escolar. A professora explica que a retirada não era apenas uma questão de nomenclatura, mas de compreensão sobre Psicologia e educação, sobre escola e sobre o modo como o psicólogo deveria atuar no campo educativo. A ideia era sair do foco individual e do aluno. Essa Psicologia educacional tradicional tinha como característica a concepção de que o papel do psicólogo era identificar aspectos das crianças que pudessem explicar o seu suposto não aprender, de modo a se pensar como ensinar a elas de maneira eficiente. Quando se muda o conceito de educação, de escola e de Psicologia, o olhar quanto a essas questões também muda.

A proposta de mudança desse olhar da Psicologia educacional e escolar deflagra o período da crítica (1981-1990). Pode-se afirmar que essa foi a década da denúncia para a Psicologia educacional e escolar. A partir da tese de doutorado de Patto, intitulada Psicologia e Ideologia: Reflexões sobre a Psicologia Escolar (1981), na qual ela investiga a prática existente no serviço de Psicologia escolar da prefeitura de São Paulo, principia uma série de críticas ao que era desenvolvido em serviços semelhantes. Na tese, Patto critica a forma como os psicólogos atuavam, baseados em pressupostos como o da teoria da carência cultural ou em explicações como déficit linguístico e problemas de aprendizagem que, especialmente, se dirigiam às crianças pobres. De modo geral, essas explicações sobre o não aprender nas escolas estavam alicerçadas a uma visão ideológica do que é ou não normalidade no contexto educativo, e, por isso, as classificações se davam a partir de um padrão normativo de aprendizagem dita adequada, cujos desviantes eram as crianças pobres.

Nas obras subsequentes de Patto $(1990,1992)$ e também no trabalho de Ivonne Khouri, (1984) encontram-se críticas a essa Psicologia educacional e do escolar tradicional, baseada na testagem, prevenção, psicoanálises e educação compensatória. Há uma contestação quanto aos referenciais teóricos e também práticos cujo alicerce era a Psicologia escolar normativa ou classificatória e disciplinatória. Essa Psicologia tradicional, segundo estas autoras, cumpria um papel de Psicologia do ajustamento, que tinha como prerrogativa o cumprimento de uma função ideológica de manter os desviantes (em geral identificados entre a classe pobre) normalizados e ajustados.

Verifica-se que, mesmo que as críticas apontassem novas formas de atuação com base em pressupostos diferenciados, houve, no momento, um afastamento do campo prático que levou os profissionais da Psicologia educacional e escolar a questionarem o papel dessa área ou as funções do psicólogo no contexto educacional e sua atuação. Um dos exemplos emblemáticos desse processo de discussão foi a realização, por iniciativa do Sindicato dos Psicólogos e do Conselho Regional de Psicologia de São Paulo, do I Encontro de Psicólogos da Área de Educação, realizado em 1980 (SINPSI, CRP-SP, 1981). Esse foi o primeiro evento no País a reunir profissionais específicos da área, e, após essa iniciativa, ocorreram mais dois encontros (Prates, 2011). As discussões nos eventos abordavam o papel do psicólogo escolar a partir das novas configurações da sociedade democrática, com reflexões sobre que bases 
e referenciais diferenciados. A Psicologia poderia se reconstruir de modo a não mais estar alicerçada naquela Psicologia tradicional normativa e classificatória.

Ainda faltam estudos que ilustrem melhor o que causou certo recrudescimento da área, mas de fato isso veio a ocorrer. Sobre esse tema, algumas hipóteses são por nós aventadas, como o fato de que foi justamente nessa época que grandes transformações políticosociais estavam em questão no País. Era a fase da redemocratização, da reivindicação pelas eleições diretas para presidência, de construção do processo constituinte, de novas legislações e de formas de funcionamento em um regime democrático, entre outros. No campo educativo, repensavam-se as estruturações anteriores que tinham no tecnicismo a base de sustentação, e buscava-se uma educação libertadora, crítica. Na Psicologia, os psicólogos passam a reivindicar seu lugar como profissionais nas políticas públicas de saúde, e engajam-se no Movimento de Luta Antimanicomial, isso para ficar em apenas alguns exemplos. De modo geral, observa-se que a crítica relativa à Psicologia educacional e escolar tradicional fez com que os profissionais da área buscassem se debruçar sobre suas referências com o fim de repensá-las e de reconstruir a área sobre outros patamares.

O sexto período, denominado a Psicologia educacional e escolar e a reconstrução (19902000), tem como característica justamente essa ressignificação dos trabalhos teóricos e práticos da área. Observa-se nessa fase o crescimento de produções científicas relacionadas a vários temas da Psicologia educacional e escolar, agora não apenas meros reprodutores de teorizações estrangeiras, mas produtores de temas sobre a formação, a fundamentação teórica e as práticas do psicólogo no contexto educativo. De todos os momentos da história da Psicologia educacional e escolar, foi nesse em que mais apareceram publicações como livros, artigos, teses, dissertações e informativos diversos com temáticas variadas sobre a área. Os termos Psicologia escolar ou Psicologia escolar crítica são os mais comumente usados no período, com o intuito de diferenciação da Psicologia educacional e escolar tradicional. Além disso, edificam-se várias proposições de trabalhos práticos nas escolas e retomam-se as discussões sobre a necessidade de oferta de serviços de Psicologia para todos os personagens do universo escolar. A visão individualista da Psicologia educacional e escolar tradicional passa a ser substituída por uma preocupação com os processos educativos de modo mais amplo e com as redes de relações constituídas no interior da escola (Prates, 2011).

Um dos marcos da época é a criação da Associação Brasileira de Psicologia Escolar e Educacional (ABRAPEE) em 1990, e da revista da entidade, cujo foco era a Psicologia em sua relação com a educação. Também inicia-se a organização dos psicólogos dessa área, que passam a se reunir bianualmente no Congresso Nacional de Psicologia Escolar (o CONPE). O Conpe tem sua primeira edição em 1990, ao final do qual foi fundada a ABRAPEE e escolhida a primeira diretoria, como nos conta Geraldina Porto Witter: "(O primeiro Conpe) foi um evento que não tinha nenhuma sociedade por trás. A associação foi criada aí. Foi feita uma assembleia... na assembleia, todos concordaram em criar a associação" (Witter em depoimento a Barbosa, 2011, p. 520). Guzzo, em depoimento para a tese (Barbosa, 2011), refere-se ao desejo de construir a ABRAPEE de forma a reunir os profissionais da área em torno de discussões sobre as teorias e práticas. Ela afirma que a associação nasceu da iniciativa de alguns professores da Pontifícia Universidade Católica de Campinas (PUCCAMP), e que, inicialmente, funcionou durante muito tempo dentro da sua própria casa por falta de sede. Aos poucos, foram construindo a associação e organizando os Conpes, que se tornaram um importante evento de encontro dos profissionais da área. 
É nessa época que podemos dizer que há a tentativa de superação da década da denúncia para a construção de novos parâmetros de pesquisa, formação e atuação em Psicologia educacional e escolar crítica. Diferentemente da perspectiva tradicional, aponta-se a necessidade de superação do modelo clínicomédico de atuação bem como do referencial psicométrico como basilar da prática. Além disso, o foco individual e a ideia de trabalhar com problemas de aprendizagem, com famílias desestruturadas e carência cultural cede lugar à concepção de fracasso escolar (Patto, 1990/2000) ${ }^{6} \mathrm{e}$, posteriormente, a problemas no processo de escolarização e atuação junto a queixas escolares (Souza, 2002). De modo geral, passa-se a compreender que o não aprender na escola não pode ser explicado por questões individuais, organicistas ou por problemas de ordem socioambiental. Graças à contribuição de Patto (1990/2000), entende-se, a partir desse novo olhar, que há um fracasso escolar produzido pela própria escola e pelo sistema educacional como um todo, e contribuem para essa construção a visão que se tem das crianças pobres e de todo um conjunto de condições macroestruturais envolvidas, como a formação docente e o pouco investimento em políticas públicas de educação, entre outros.

A Psicologia educacional e escolar passa, assim, a ter como principal foco a compreensão não do porque a criança não aprende, e sim, do que ocorre no processo de escolarização

6 É importante destacar que esta visão crítica entretanto não foi consenso na área, sendo necessário afirmar que a Psicologia Educacional tradicional, através de alguns autores ainda tem forte influência. que produz aquele que supostamente não aprende. Segundo Souza, essa mudança na pergunta enseja toda uma transformação no modo como os psicólogos passam a trabalhar e também uma necessidade de nova formação profissional. O olhar, antes individualizado e centralizado no aluno, ou no professor, ou na escola, passa a priorizar todos os personagens do universo escolar, bem como as relações intraescolares, as políticas públicas educacionais, as condições econômicas, sociais, culturais e políticas de determinado contexto. Embora não de forma consensual e única, é com este espírito de renovação da área, por meio da Psicologia escolar crítica que se estabelecem novas bases e principiam os anos 2000.

A análise de um período recente da história é algo complexo dadas as características desse tipo de trabalho, e, nesse sentido, o sétimo período, a virada do século: novos rumos? (2000-); é um questionamento a futuros pesquisadores que queiram adentrar nos anos 2000 até os dias atuais de forma a caracterizar esse momento. O que se pôde construir sobre essa fase, a partir do trabalho de doutorado aqui descrito, é que estamos ainda em um tempo de reconfigurações, olhando para nosso passado tentando avaliar o presente com a finalidade de renovar nossas teorias e práticas no futuro. Sabe-se que muito se construiu até os anos 2000, porém ainda não temos a dimensão de como todas essas transformações se articularam nos dias atuais. O que podemos afirmar sobre essa fase ainda é incipiente, mas nota-se que, a partir dos anos 90, a produção intelectual e acadêmica da área foi vertiginosa. Cabe-nos agora compreender como esses referenciais estão chegando aos profissionais que atuam nesse campo.

De modo geral, o que podemos vislumbrar é que atualmente existem vários serviços públicos de Psicologia educacional e escolar ligados a iniciativas de prefeituras e também atuações nas escolas privadas por meios de psicólogos consultores. Porém, ainda precisamos conhecer como têm chegado de fato a esses profissionais que estão na prática as produções dos meios acadêmicos (Souza, 2010). É por isso que, utilizando uma expressão do livro Psicologia Escolar em Busca de Novos Rumos (Machado \& Souza, 1997), uma das referências mais utilizadas atualmente pelos profissionais da área para balizar suas práticas e teorizações, propomos o questionamento novos rumos? Será que conseguimos construí-los? Em nossa análise da tese, não 
... a Psicologia educacional e escolar é uma das principais responsáveis por erigir a Psicologia como um todo no país. foi possível responder esse questionamento, que tem sido inclusive alvo de pesquisas atuais na área, porém é possível vislumbrar que existem novas configurações nesse campo (Souza, 2010). No último Congresso Nacional de Psicologia Escolar e Educacional (CONPE), em Maringá, no ano 2011, por exemplo, foi possível verificar a existência de atuações em vários setores, como Centros de Referência em Assistência Social, trabalho junto a organizações não governamentais, abrigos e centros de internação de crianças que cumprem medidas socioeducativas, entre outros. Isso denota maior expansão do trabalho desse profissional, bem como se pôde observar, por meio dos relatos de experiências, que essas práticas têm procurado superar $\mathrm{o}$ modelo tradicional, abarcando o paradigma crítico.

Nesse sentido, o que é importante destacar é que são novos os contextos educativos em que o psicólogo tem sido chamado a atuar, e, pelas discussões anteriores sobre as diferenças entre Psicologia escolar tradicional e crítica, nota-se não só a emergência de novos rumos mas também as novas necessidades de atuação junto a novos públicos-alvo, novas políticas e práticas são prementes. Tudo isso convida-nos a encerrar esse longo trajeto histórico ressaltando que talvez a resposta a esse questionamento seja a de que estamos trilhando novos rumos. Quais? O tempo irá dizer.

O trabalho de tese, assim como este texto, encerra-se não com conclusões, mas com algumas considerações acerca desse histórico. Uma delas é o fato de que a Psicologia educacional e escolar é uma das principais responsáveis por erigir a Psicologia como um todo no nosso país. Além disso, foi a partir dessa área que se pôde, mesmo que a partir do movimento de testes e da Psicologia do ajustamento (nossa Psicologia aplicada), fundamentar as práticas iniciais em serviços de Psicologia. E, finalmente, assim como compreendemos, a partir de uma visão marxista, que esta sociedade é contraditória por excelência, também podemos afirmar o mesmo quanto à Psicologia e à Psicologia em sua relação com a educação. Se esta serviu aos propósitos de ajuste, de classificação e de discriminação, também contribuiu para a emergência de novas formas de viver nesta sociedade, que possui sistema educacional e escola desigual e injusta. Em outras palavras, verificou-se que a história da Psicologia educacional e escolar nos diferentes momentos pelos quais passou foi marcada por continuidades, descontinuidades, rupturas, reconstruções, resistências e por uma discussão permanente de seu papel como área a serviço de interesses ora conservadores, ora emancipatórios e libertadores. Nos dizeres de Patto no depoimento para a tese, a escola é uma caixa de ressonância desta sociedade contraditória, e o que a autora diz da escola, acredito que se aplique perfeitamente também à Psicologia em sua relação com a educação:

(...) Ao mesmo tempo que ideologiza, adapta e disciplina para formar cidadãos exemplares, produtivos e que não questionam, ela também abre a possibilidade de contato com ideias na contramão, de reflexões. $E$ faz isso principalmente pelo fato de alfabetizar, de propiciar aos educandos ferramentas, instrumentos de compreensão da vida social e de suas próprias vidas (Patto em depoimento a Barbosa, 2011, p. 642)

Acredito que a história dessa área nos permita afirmar que se abriu a possibilidade de a Psicologia educacional e escolar, a partir da perspectiva crítica, oferecer ferramentas, instrumentos que possam ajudar nos processos educativos em contextos educacionais diversos. Podemos oferecer elementos que colaborem para a compreensão e a ampliação da consciência e dos sentidos da vida social e da vida das pessoas. Além disso, a história nos mostra que ainda é possível construir teorizações, uma formação e uma prática com propósitos emancipatórios e libertadores. Para tanto, é necessário que os profissionais da área 
estejam comprometidos ética e politicamente com a mudança e com novas formas de organização e de produção no campo educativo que sejam efetivamente alicerçadas nos propósitos de libertação da opressão e da desigualdade social. Acreditamos que isso possa se concretizar futuramente se contribuirmos para a propagação desse novo olhar, pois "(...) há que se cuidar do broto pra que a vida nos dê flor e fruto" (Milton Nascimento \& Wagner Tiso, 1983).

\section{Deborah Rosária Barbosa}

Doutora em Psicologia Escolar e do Desenvolvimento Humano pelo Instituto de Psicologia da Universidade de São Paulo, integrante do Laboratório Interinstitucional de Estudos e Pesquisas em Psicologia Escolar (LIEPPE-USP), Professora da Universidade de Mogi das Cruzes, São Paulo - SP - Brasil.

E-mail: deborahbarbosa@yahoo.com.br ou deborahbarbosa@usp.br

Endereço para envio de correspondência:

Rua Caraíbas 172, Perdizes, São Paulo - SP - Brasil. CEP: 05020-000

Referências
Aguiar, W. M. J \& Ozella, S. (2006). Núcleos de significação como instrumento para a apreensão da constituição dos sentidos. Psicologia: Ciência e Profissão, 26(2), 222-245.

Antunes, M. A. M. (1991). O processo de autonomização da Psicologia no Brasil - 1890/1930: uma contribuição aos estudos em história da Psicologia. Tese de doutorado. Psicologia Social, Pontifícia Universidade Católica de São Paulo, São Paulo, SP.

Antunes, M. A. M. (1996). Algumas reflexões acerca de minha formação como pesquisadora em história da psicologia. In R. H. F. Campos, (Org.), História da psicologia (pp. 95-104). São Paulo: EDUC/ANPEPP.

Antunes, M. A. M. (2001). A Psicologia no Brasil: uma leitura histórica sobre sua constituição (2a. ed.). São Paulo: Educ/Unimarco.

Antunes, M. A. M. (2003). Psicologia e educação no Brasil: um olhar histórico-crítico. In M. E. M. Meira, \& M. A. M. Antunes, (Orgs.), Psicologia escolar: teorias críticas (pp. 139-168). São Paulo: Casa do Psicólogo.

Antunes, M. A. M. (2006). A consolidação da psicologia no Brasil (1930-1962): sistematização de dados e algumas aproximações analíticas. Psicologia da Educação, 22, Recuperado em 07 fevereiro, 2007, de Portal PePSIC - http://pepsic.bvsalud.org/scielo. php?script $=$ sci_arttext\&pid $=$ S1414-69752006000100005\&lng= n\&nrm = nd

Antunes, M. A. M. (2007). Psicologia escolar e educacional: história, compromissos e perspectivas. Cadernos de Psicopedagogia, 6(11), Recuperado em 12 janeiro, 2008, de Portal PePSIC http:// pepsic.bvsalud.org/scielo.php?script $=$ sci arttext\&pid $=$ S1676$10492007000100008 \& \operatorname{lng}=\mathrm{es} \& n r m=\mathrm{nd} \overline{\mathrm{Q}} \operatorname{tnn}=\mathrm{es}$

Antunes, M. A. M. (2011). Psicologia e educação no Brasil: uma análise histórica. In R. G. Azzi, \& M. H. T. Gianfaldoni, (Orgs.), Psicologia e educação (pp. 9-32). São Paulo: Casa do Psicólogo.

Araújo, S. F. (2007). A fundamentação filosófica do projeto de uma psicologia científica em Wilhelm Wundt. Tese de doutorado. Departamento de Filosofia do Instituto de Filosofia e Ciências
Humanas da Universidade Estadual de Campinas, Campinas, SP.

Barbosa, D. R. (2011). Estudos para uma história da psicologia educacional e escolar no Brasil. Tese de doutorado. Programa de Pós-Graduação em Psicologia Escolar e do Desenvolvimento Humano, Instituto de Psicologia, Universidade de São Paulo, SP.

Bardin, L. (1995). Análise de conteúdo. (L. A. Reto \& A. Pinheiro, trads.). Lisboa: Edições 70.

Bernardes, J. S. (2004). O debate atual sobre a formação em psicologia no Brasil: permanências, rupturas e cooptaçốes nas políticas educacionais. Tese de doutorado. Pontifícia Universidade Católica de São Paulo, São Paulo, SP.

Bosi, E. (2003). O tempo vivo da memória: ensaios de psicologia. São Paulo: Ateliê Editorial.

Brasil. (1890). Decreto $n^{\circ}$. 980, de 8 de novembro de 1890 - Dá novo regulamento ao Pedagogium da Capital Federal. Brasília, DF: Senado Federal.

Brasil. (1962). Lei $n^{o}$. 4.119 de 27 de agosto de 1962. Dispõe sobre os cursos de formação em Psicologia e regulamenta a profissão de psicólogo. Brasília, DF: Presidência da República.

Brasil. (1962). Resolução de 19 de dezembro de 1962, fixa o currículo mínimo e a duração do Curso de Psicologia. Brasília, DF: Conselho Federal de Educação.

Brasil. (1964). Decreto $n^{\circ} .53 .464$ de 21 de janeiro de 1964. Regulamenta a Lei $n^{\circ} .4 .119$, de agosto de 1962, que dispõe sobre a profissão de psicólogo. Brasília, DF: Presidência da República.

Brasil. (1977). Decreto $n^{\circ}$. 79.822 de 17 de julho de 1977. Regulamenta a Lei 5.766/71. Brasília, DF: Presidência da República.

Brecht, B. (1982). Antologia poética. Rio de Janeiro: Elo. 
Cambi, F. (1999). História da pedagogia (Á. Lorencini, trad.). São Paulo: Fundação Editora da UNESP (FEU).

Centofanti, R. (1982). Radecki e a psicologia no Brasil. In M. A. M. Antunes (Org.), História da psicologia no Brasil: primeiros ensaios (pp. 177-208). Rio de Janeiro: EDUERJ/Conselho Federal de Psicologia.

Centofanti, R. (2006). Os laboratórios de psicologia nas escolas normais de São Paulo: o despertar da psicometria. Psicologia da Educação, 22, 31-52.

Clio-Psyché - Universidade Estadual do Rio de Janeiro. (2008) Clio-psyché website. Recuperado em 4 julho, 2010, de http:// www.cliopsyche.uerj.br

Cotrin, J. T. D. (2010). Itinerários da psicologia na educação especial: uma leitura histórico-crítica em psicologia escolar. Tese de doutorado. Instituto de Psicologia, Universidade de São Paulo, São Paulo, SP.

Figueiredo, L. C. M., \& Santi, P. L. R. (2004). Psicologia, uma (nova) introdução: uma visão da psicologia como ciência. São Paulo: EDUC.

Goodwin, C. J. (2005). História da psicologia moderna. (M. Rosas, trad.). São Paulo: Cultrix.

Hobsbawm, E. (1998). Sobre história. (C. Knipel Moreira, trad.). São Paulo: Cia das Letras.

Khouri, Y. G. (Org.). (1984). Psicologia escolar. São Paulo: EPU.

Machado, A. M., \& Souza, M. P. R. (Orgs.). (1997). Psicologia escolar: em busca de novos rumos. São Paulo. Casa do Psicólogo.

Marx, K. (1977). Teses sobre Feuerbach. In K. Marx \& F. Engels. Textos: Vol. I (pp. 118-120). São Paulo: Ed. Alfa-Omega (Trabalho original publicado em 1888).

Marx K. Engels, F (2007). A ideologia alemã: crítica da mais recente filosofia alemã em seus representantes Feuerbach, B. Bauer e Stiner, e do socialismo alemão em seus diferentes profetas. (R. Enderle, N. Schneider \& L. Cavini Martorano, trads.). São Paulo: Boitempo (Trabalho original publicada em 1845).

Massimi, M. (1984). História das idéias psicológicas no Brasil em obras do período colonial. Dissertação de mestrado. Universidade de São Paulo, São Paulo, SP.

Massimi, M. (1990). História da psicologia brasileira: da época colonial até 1934. São Paulo: EPU.

Massimi, M., \& Guedes, M. C. (Orgs). (2004). História da psicologia no Brasil: novos estudos. São Paulo: EDUC, Cortez.

Massimi, M.; Mahfoud, M. ; Silva, P. J. C. \& Avanci, S. H. (Orgs.). (1997). Navegadores, colonos, missionários na Terra de Santa Cruz: um estudo psicológico da correspondência epistolar. São Paulo: Loyola.

Meihy, J. C. S. (2000). Manual de história oral. São Paulo: Loyola.

Nascimento, M., \& Tiso, W. (1983). Coração de estudante. In Milton Nascimento ao vivo. Barclay/Ariola. [CD].

Patto, M. H. S. (1981). Psicologia e ideologia: reflexões sobre a psicologia escolar. Tese de doutorado. Instituto de Psicologia, Universidade de São Paulo, São Paulo, SP.

Patto, M. H. S. (1992). A família pobre e a escola pública: anotações sobre um desencontro. Psicologia USP, 3(1), 107-121.

Patto, M. H. S. (2000). A produção do fracasso escolar: histórias de submissão e rebeldia. (2a ed.). São Paulo: Casa do Psicólogo, 2000 (Trabalho original publicado em 1990).

Paulo Netto, J. (1998). Relendo a teoria marxista da história. In
D. Saviani et. al. (Org.), História e história da educação: o debate teórico-metodológico atual (pp. 74-84). Campinas, SP: Autores Associados

Penna, A. G. (1981). História das idéias psicológicas. Rio de Janeiro: Zahar.

Pettirossi, A., \& Lombardi, J. C. (1997). Levantamento e catalogação das fontes para o estudo histórico da educação brasileira existentes na região de Campinas: prof. Norberto Souza Pinto, um estudo histórico-biográfico. In Anais do IV Seminário Nacional de Estudos e Pesquisas História, Sociedade e Educação no Brasil (p. 114). Campinas, SP: Faculdade de Educação, Universidade de Campinas, SP.

Pfromm Netto, S. (1979). A psicologia no Brasil. In M. G. Ferri \& S. Motoyama (Coords.). História das ciências no Brasil (pp. 236-276). São Paulo: EPU/EDUSP.

Pfromm Netto, S. (1996). As origens e o desenvolvimento da psicologia escolar. In S. M. Wechsler (Org.), Psicologia escolar: pesquisa formação e prática (pp. 22-38). Campinas, SP: Alínea.

Pimentel, A. (2001). O método de análise documental: seu uso numa pesquisa historiográfica. Cadernos de Pesquisa, 114, 179-195.

Portelli, A. (1997). O que faz a história oral diferente. Projeto História, $14,25-39$.

Prates, E. F. (2011). Para uma história crítica da psicologia escolar em São Paulo. Trabalho de conclusão de curso. Universidade Presbiteriana Mackenzie, Centro de Ciências Biológicas e da Saúde, Curso de Psicologia. São Paulo.

Prestes, A. L. (2010). O historiador perante a história oficial. Germinal: marxismo e educação em Debate, 1(2), 91-96.

Schmidt, M. L. S., Sekkel, M. C., Souza, M. P. R., Barbosa, D. R \& Santos, A. A. (Orgs.). (2010). Programa de pós-graduação em psicologia escolar e do desenvolvimento humano: 40 anos. São Paulo: Instituto de Psicologia.

Schultz, D. P. \& Schultz, S. E. (2002). História da psicologia moderna (15a ed., A. U. Sobral \& M. S. Gonçalves, trads.). São Paulo: Cultrix.

Sindicato dos Psicólogos do Estado de São Paulo \& Conselho Regional de Psicologia (6- Região) (1981). In Anais do I Encontro de psicólogos da área de educação. São Paulo: Sinpsi/CRP-SP.

Souza, M. P. R. (2002). Problemas de aprendizagem ou problemas de escolarização? In Abrapee. Boletim Eletrônico. Recuperado em 23 jan., 2009, da ABRAPEE: http://www.abrapee.psc.br/artigo5.htm

Souza, M. P. R. (2010). A atuação do psicólogo na rede pública de educação: concepcôes, práticas e desafios. Tese de Livre-docência, Instituto de Psicologia, Universidade de São Paulo, São Paulo, SP.

Tanamachi, E. R. \& Meira, M. E. M. (2000). Psicologia escolar: pensamento crítico e práticas profissionais. In E. R. Tanamachi, M. Proença, M. L. Rocha (Orgs.), Psicologia e educação: desafios teórico-práticos (pp. 35-71). São Paulo: Casa do Psicólogo.

Taverna, C. S. R. (2003). Um estudo histórico sobre a psicologia escolar na Secretaria Municipal de Educação da Prefeitura. Tese de doutorado. Pontifícia Universidade Católica de São Paulo, São Paulo, SP.

Thompson, P. (2002). A voz do passado: história oral (3a. ed., L. L. de Oliveira, trad.). Rio de Janeiro: Paz e Terra.

Waeny, M. F. C., \& Azevedo, M. L. B. (2009). A psicologia escolar e sua história. In Conselho Regional de Psicologia de São Paulo/Projeto Memória da Psicologia em São Paulo. Recuperado em 16 março 2009, de CRP-SP: http://www.crpsp.org.br/memoria/educacao/ artigo educacao.aspx 